\title{
FEATURES OF MICROBAL CENOSIS FORMING OF ALNUS GLUTINOSA (L.) GAERTN. ROOT SOIL
}

\author{
Ellanskaya Nataliia*, Gorelov Alexei
}

M.M. Gryshko National Botanical Garden, NAS of Ukraine, Kyiv, Ukraine

\section{ОСОБЕННОСТИ ФОРМИРОВАНИЯ МИКРОБНОГО ЦЕНОЗА ПРИКОРНЕВОЙ ПОЧВЫ ALNUS GLUTINOSA (L.) GAERTN.}

\section{Элланская Наталия, Горелов Алексей}

Received 17.6. 2017

Revised 22.6. 2017

Published 27. 11. 2017

\begin{abstract}
This article gives the results of microbiological and mycological researches of Alnus glutinosa (L.) Gaertn. root soil. The purpose of this study was to investigate the characteristics of microbial communities and their biological activity in the Alnus glutinosa plant's root zone. The Alnus glutinosa 10 years age plants were studied in the experimental fields of the NSC Panfil Experimental Station. Microbiological investigations were carried out by conventional methods - seeding of certain dilutions of soil suspension on selective cultural medium. The allelopathic activity was analyzed by bioassays method. The comparative characteristic of microbial groups and allelopathic activity were investigated dynamically according to the Alnus glutinosa plants development phases. A quantity of actinomycetes gradual increases in spring and reduction in summer and autumn. The actinomycetes development depended on soil hydrothermal conditions. The micromycetes and ammonifiers number in the Alnus glutinosa root zone were much higher than control variation. The largest quantity of soil nitrogen consumption microorganisms was observed in summer. The soil organic matter accumulation dominated at the beginning and the end of vegetation period, whereas activation of mineralization processes occurred in summer. The number of cellulolytic microorganisms increased in the autumn, which is due to the introduction of plant residues into the soil cellulolytic activity rate correlated to cellulolytic microorganisms' number but were significantly low. We observed the intensive growth of Azotobacter chroococcum in the root zone. It was shown that the root secretion of test plants had a small allelopathic activity. Thus, the intensity of microbiological processes depends on the season, environmental conditions and plant metabolites.
\end{abstract}

Keywords: Alnus glutinosa; microbial communities; cellulolytic activity; root soil

\section{Введение}

Хозяйственное значение ольхи черной (Alnus glutinosa (L.) Gaertn.) очень большое. Прежде всего, она является лесообразующей и мелиорирующей породой на труднодоступных и неиспользуемых человеком заболачивающихся участках, трясинах, мочажниках и прочих неудобных землях. Ольха скрепляет почву своей обильно разрастающейся корневой системой, обогащает ее азотом, улучшает структуру и повышает плодородие, создавая тем самым условия для произрастания здесь других пород.

*Corresponding author: Nataliia Ellanskaya, M.M. Gryshko National Botanical Garden, NAS of Ukraine, Kyiv, Ukraine, $\triangle$ n.ellanska@gmail.com 
Одним из консортов фитоценозов являются микроорганизмы, находящиеся в тесных взаимоотношениях с почвой и растениям. Они выполняют важную функцию в круговороте веществ в биосфере - разлагают и минерализуют органические вещества и синтезируют азотные соединения (Волкогонов та ін., 2010).

Предыдущие наши исследования охватывали проблему имматурных растений ольхи разных видов (Елланська і Горєлов, 2012; Елланська та ін., 2013). Поскольку именно Alnus glutinosa оказалась довольно аллелопатически активным видом, а ее ризосфера отличалась самым большим количеством микроорганизмов всех эколого-трофических групп, это и побудило нас провести дальнейшие работы уже со взрослыми растениями.

Цель работы - изучение микробных сообществ прикорневой почвы и ее биологической активности под растениями ольхи черной.

\section{Материалы и методы}

Эксперименты проводили на осушаемых органогенных почвах Панфильской опытной станции ННЦ «Институт земледелия НААН» в заплаве р. Супой, левобережной Лесостепи Киевской области. Почвы карбонатные (37 - 49\%), $\mathrm{pH}$ 7,3 - 7,8, глубина залегания торфа 3 - 4 м, его разложение в пахотном слое составляет 65 - 70 \%. Образцы почвы для исследований отбирали в прикорневой зоне 10-ти летних растений ольхи черной по фазам развития: начало формирования ассимиляционной системы и линейного роста побегов (апрель), завершение формирования побеговой системы (июль), конец вегетации (октябрь).

Выделение микроорганизмов из свежеотобранных образцов почвы осуществляли методом посева почвенных суспензий соответствующих разведений на селективные агаризованные питательные среды по общепринятым в почвенной микробиологии методикам (Теппер, 2005). Направленность микробиологических процессов, целлюлозолитическую и аллелопатическую активность определяли соответственно описанному ранее (Елланська та ін., 2013). Как контроль была использована почва, не подвергающаяся аллелопатическому влиянию растений ольхи. Статистическая обработка данных проведена при помощи пакета программ Microsoft Excel.

\section{Результаты и их обсуждение}

В результате проведенных исследований выявлено, что максимальное количество актиномицетов в корневой зоне Alnus glutinosa отмечено в весенний период, а снижение их численностилетоми осенью, вероятно, связаноснедостаткомвлагивпочве (засушливыйпериод длился 3 месяца) (рис. 1, А). Количество микромицетов (рис. 1, Б), также как и аммонификаторов (рис. 1, В), намного превышает контрольные значения во все сроки отбора, что свидетельствует об обогащении почвы органическим веществом растительного происхождения. Динамика численности микроорганизмов-иммобилизаторов минерального азота в корневой зоне Alnus glutinosa имеет значительную амплитуду колебаний - весной их количество было минимальным, летом значительно возрастало, а к осени возвращалось почти к исходным данным (рис. 1, Г), Такой летний «пик» позволяет судить об ускоренном процессе минерализации свежего органического вещества, что и подтвердилось показателем коэффициента минерализации (если весной его значения были невысоки - 0,4, то летом составили 1,6) (рис. 1, Д). Динамика показателей трансформации органического вещества почвы имела обратную закономерность относительно коэффициента минерализации (рис. 1, Ж).

Следуетотметитьзначительноеувеличениеколичествацеллюлозолитическихмикроорганизмов осенью, что связано с поступлением в почву растительных остатков (рис. 1, 3). Поскольку целлюлоза является основным компонентом растительных остатков, интенсивность разложения клетчатки зависит от численности и активности целлюлозолитических микроорганизмов и служит важным показателем биологической активности почвы (Головко и др., 1982). 

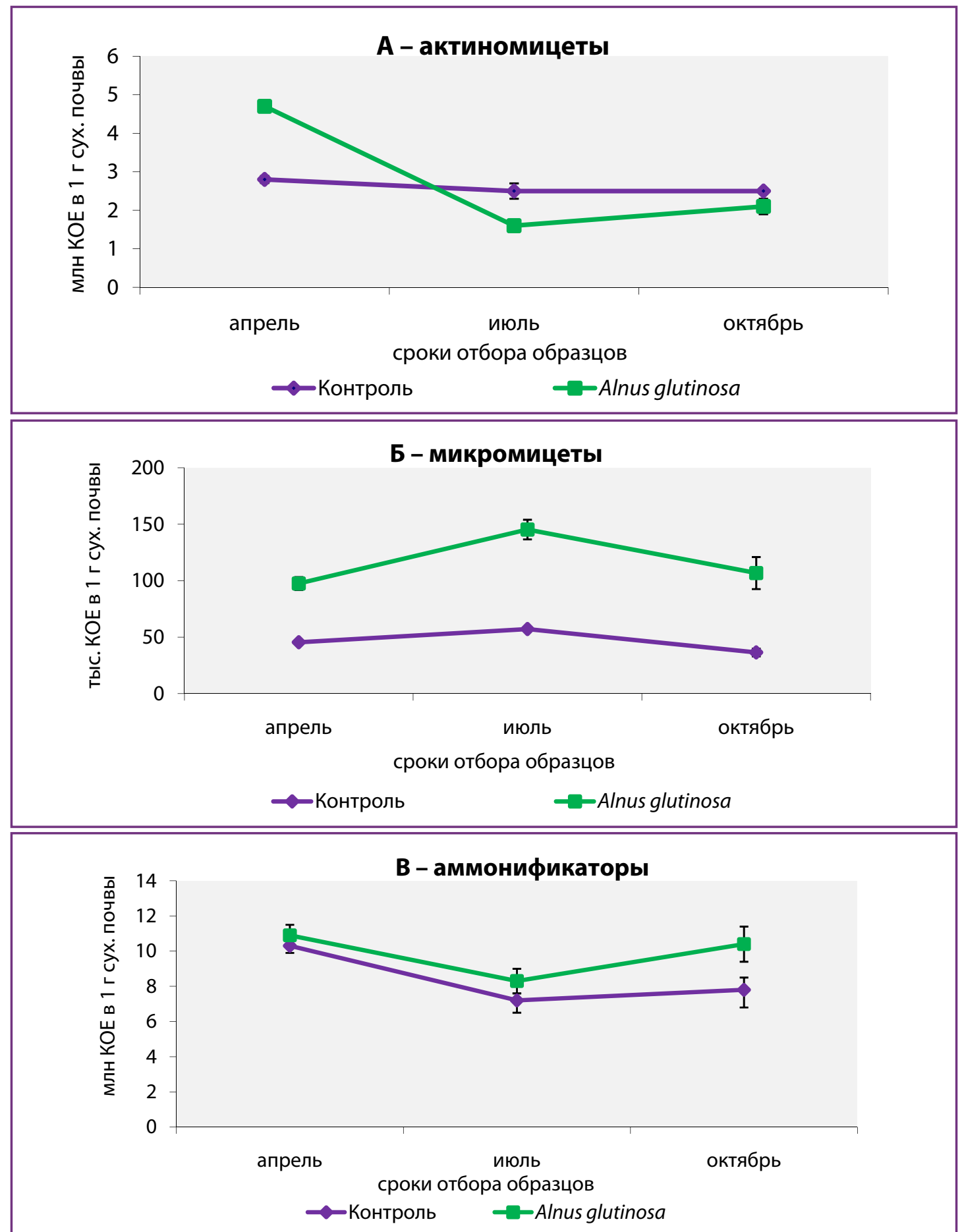

Рисунок 1 А - В Численность микроорганизмов основных таксономических и эколого-трофических групп, направленность микробиологических процессов в почве под ольхой

Figure 1 A - B The main microorganisms taxonomic and ecological-trophic groups number, the orientation of microbiological processes in the soil under alder 

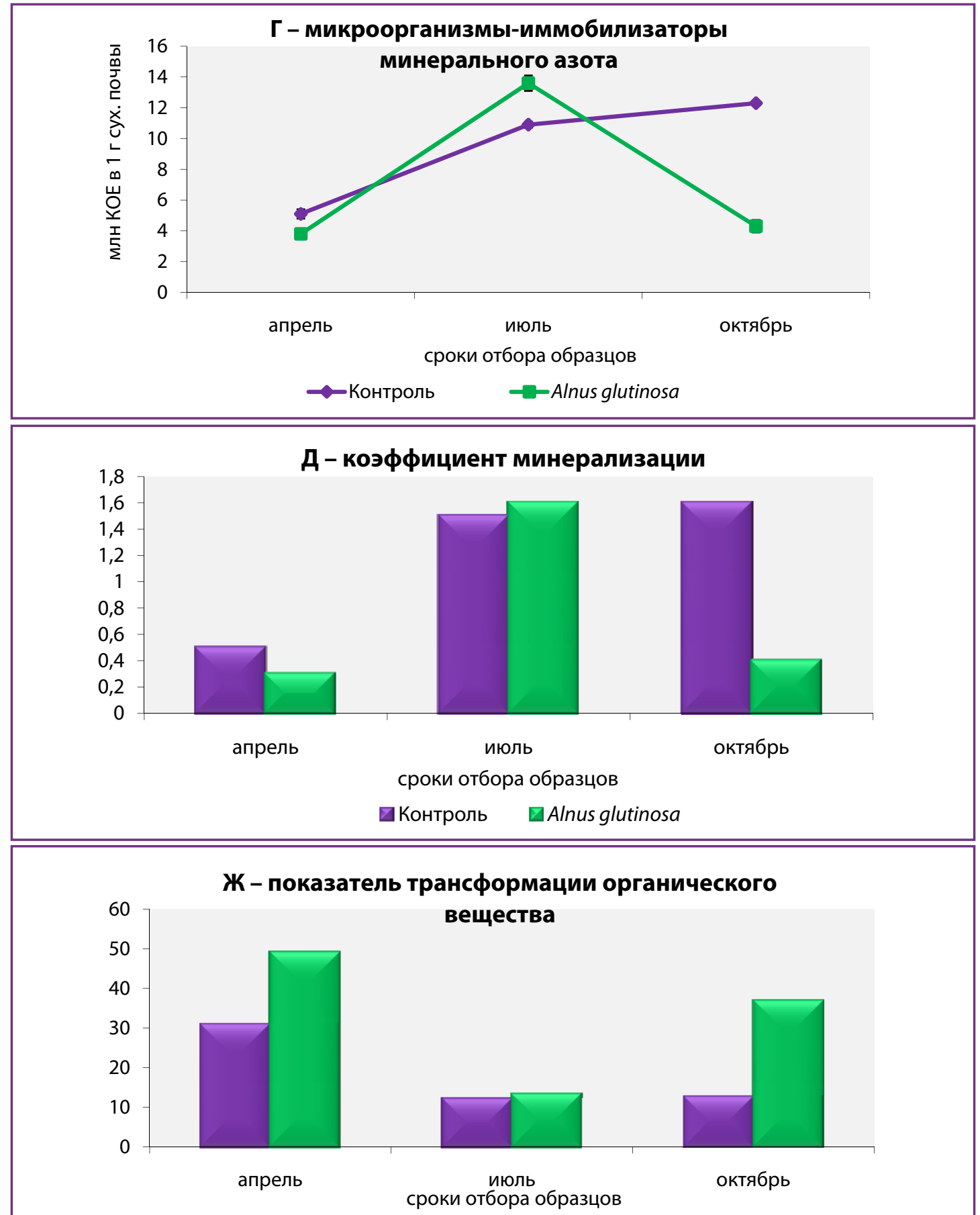

ВКонтроль

$\square$ Alnus glutinosa

Рисунок 1 Г - Ж Численность микроорганизмов основных таксономических и эколого-трофических групп, направленность микробиологических процессов в почве под ольхой

Figure $1 \Gamma-\boldsymbol{\Psi}$ The main microorganisms taxonomic and ecological-trophic groups number, the orientation of microbiological processes in the soil under alder 

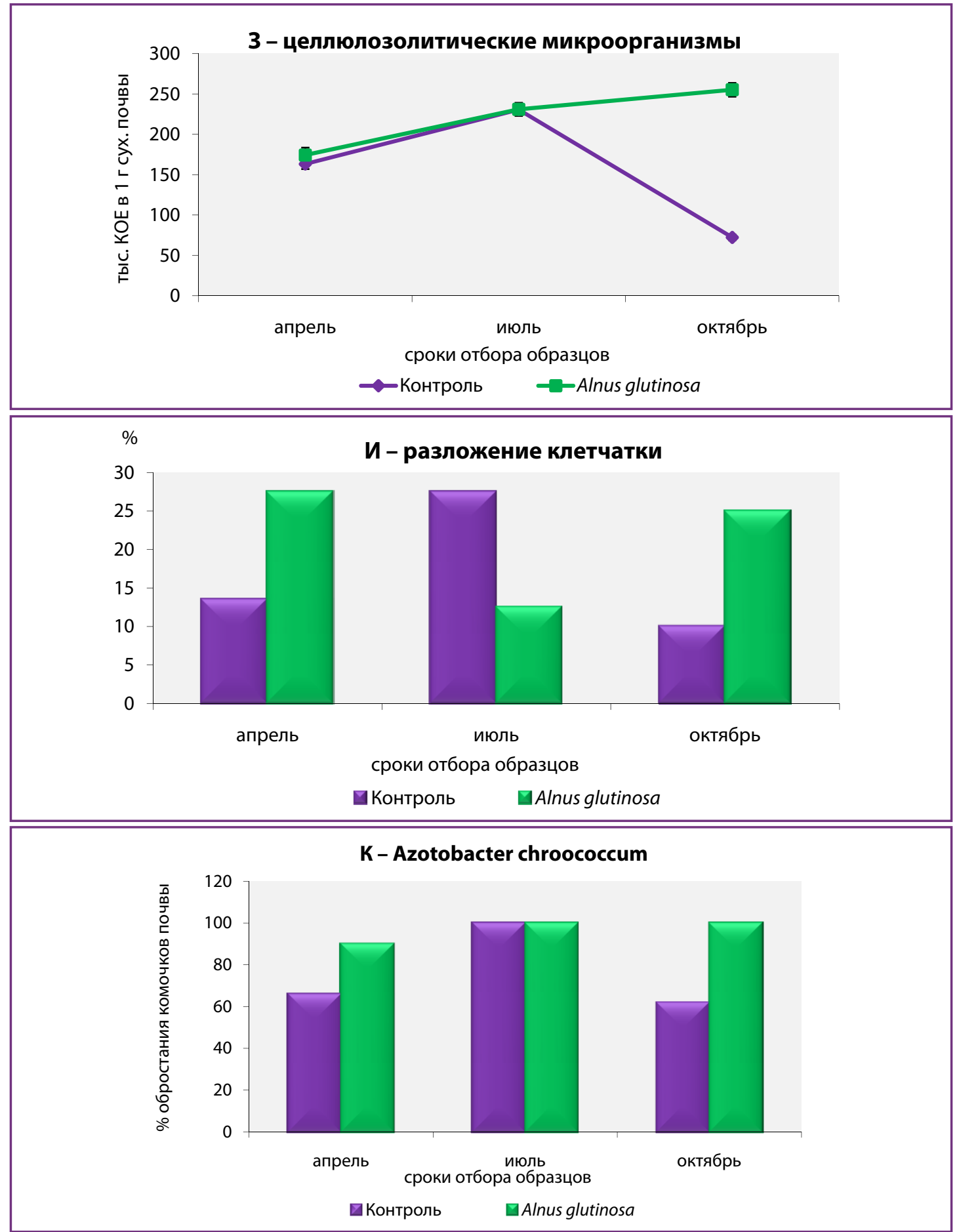

Рисунок 13 - К Численность микроорганизмов основных таксономических и эколого-трофических групп, направленность микробиологических процессов в почве под ольхой

Figure 13 - K The main microorganisms taxonomic and ecological-trophic groups number, the orientation of microbiological processes in the soil under alder 


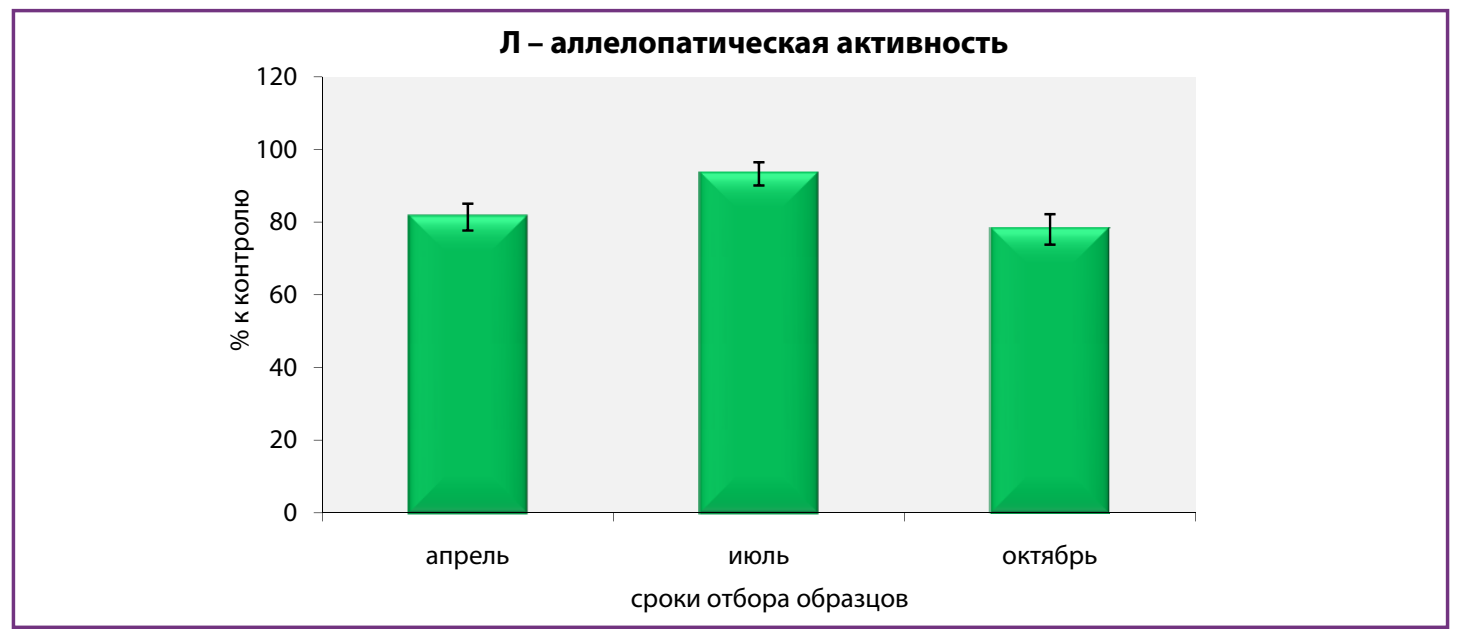

Рисунок 1 л Численность микроорганизмов основных таксономических и эколого-трофических групп, направленность микробиологических процессов в почве под ольхой

Figure 1 л The main microorganisms taxonomic and ecological-trophic groups number, the orientation of microbiological processes in the soil under alder

В опыте целлюлозолитическую активность оценивали по степени разложения фильтровальной бумаги на среде Гетчинсона. Ее значения коррелировали с численностью целлюлозолитических микроорганизмов (за исключением летнего отбора), но были довольно низки и не превышали 27,5\% (рис. 1, И).

В отличие от контрольной почвы, негативного влияния экзометаболитов растений ольхи на рост свободноживущей азотфиксирующей бактерии Azotobacter chroococcum не отмечено (рис. 1, К). Также почва под ольхой не проявила значительной аллелопатической активности (рис. 1, Л).

\section{Выводы}

Микробиологический и аллелопатический анализы почвы под Alnus glutinosa свидетельствует о том, что корневые выделения растения создают благоприятные условия для жизнедеятельности микроорганизмов. Интенсивность микробиологических процессов зависит от сезона, метеорологических условий и экзометаболитов растений.

\section{Литература}

Волкогонов, В.В., Надкреничная, О.В., Толмакова, Л.М., Мельничук, Т.М., Чайковська, Л.О. 2010. Експериментальна грунтова мікробіологія. К. : Аграрна наук. 464 с.

Головко, Э.А. Элланская, Н.А. Кострома, Е.Ю. 1982. Аллелопатическое почвоутомление и фитотоксические свойствапочвенныхмикроскопическихгрибов. Аллелопатиявестественных и исскуственных фитоценозах. К. : Наук. думка. с. 86-95.

Елланська, Н.Е., Горелов, О.О. 2012. Ґрунтова мікробіота представників роду Вільха (Alnus Mill.) Вісник прикарпатського нац. ун-ту ім. Василя Стефаника. Серія Біологія, Вип. XVI, с. 46-51.

Елланська, Н.Е., Горєлов, О.О. Дзюба, О.І. 2013. Алеллопатична характеристика деяких видів роду Alnus Mill. Інтродукція рослин, № 4, с. 104-108.

Елланська, Н.Е. Левчик, Н.Я. Юношева, О.П. 2013. Мікробні угруповання прикореневого ґрунту представників роду Vitex L. Gruntoznavstvo. Soil science, т. 14, № 1-2 (22), с. 61-69.

Теппер Е.3. Шильникова, В.К. Переверзєва, Г.И. 2005. Практикум по микробиологии. М. : Дрофа. 256 с. 